\title{
Respiratory muscle function in cystic fibrosis
}

\author{
Anne Mier, Andrew Redington, Conor Brophy, Margaret Hodson, Malcolm Green
}

\begin{abstract}
Maximal static expiratory and inspiratory mouth pressures (PEmax and PImax) and quadriceps femoris muscle strength were measured in 25 patients aged 16-28 years with cystic fibrosis (mean FEV $_{1} 46 \%$ predicted). Mean (SD) Pemax was $64 \%(18 \%)$ predicted (below $75 \%$ predicted in 16 of the 25 patients), and PImax was $64 \%(24 \%)$ predicted (below $75 \%$ predicted in 14 patients). Quadriceps muscle strength was 68\% (20\%) predicted (below $75 \%$ predicted in 17 patients). The relatively small reduction in respiratory muscle strength in these patients was unlikely to have contributed appreciably to their respiratory problems.
\end{abstract}

It is well known that malnutrition may result in reduced diaphragm muscle weight ${ }^{1}$ and reduced respiratory muscle strength. ${ }^{2}$ As patients with cystic fibrosis are often malnourished it has been suspected that such patients might have reduced respiratory muscle strength. Although one study has shown reduction of maximal static respiratory pressures, ${ }^{3}$ others have not. ${ }^{4-7}$ The strength of different skeletal muscles has not been assessed in patients with cystic fibrosis. We therefore recorded maximal static respiratory pressures in a group of patients with cystic fibrosis and compared them with the strength of the quadriceps femoris muscle.

\section{Methods}

Studies were performed on 25 patients with cystic fibrosis (18 male, seven female) who had a chronic cough and evidence of chronic pulmonary infection. None had an exacerbation of pulmonary infection in the previous three months. All the patients had been performing chest physiotherapy at least twice daily since childhood. Their ages ranged from 16 to 28 (mean 21) years, their weight from 35 to 63 (mean 52 ) $\mathrm{kg}(70-103 \%$ (mean $85 \%$ ) predicted), and their height from 153 to 178 (mean 165 ) $\mathrm{cm}$. One patient was a smoker and one was an ex-smoker. All gave written informed consent to the studies, which had ethical committee approval.

Global respiratory muscle strength was assessed by measuring maximal static expiratory mouth pressure (PEmax) at total lung capacity (TLC) and maximal static inspiratory pressure (PImax) at residual volume (RV). A conventional mouthpiece and nose clip were used. PImax values have been given a positive sign for simplicity. The highest recorded pressure maintained for one second was measured with a Validyne differential pressure transducer (MP 45-28, $\pm 250 \mathrm{~cm}$ $\mathrm{H}_{2} \mathrm{O}$ ). Normal values were taken from Wilson et al. ${ }^{8}$ Quadriceps femoris muscle strength was assessed as the maximal voluntary contraction of the quadriceps muscle, measured with the patient seated in an adjustable, straight backed chair with the lower leg dependent and the knee flexed to 90 degrees. ${ }^{9}$

All manoeuvres were repeated from four to 10 times with suitable rest pauses until a plateau value had been reached and no further learning effect was seen. The best manoeuvre was used for the analysis. Normal values for maximal voluntary contractions were taken from data previously established for normal volunteers in this laboratory.

The forced expiratory volume in one second $\left(\mathrm{FEV}_{1}\right)$ was calculated from a record of forced vital capacity (FVC) performed on an Ohio spirometer (Spiroflow). Peak expiratory flow was measured with a Wright peak flow meter. Absolute lung volumes were measured in a constant volume whole body plethysmograph. All volumes were corrected to BTPS. Transfer factor for carbon monoxide (TLCO) was estimated by the single breath method and from this the gas transfer coefficient (Kco) was derived. Normal values were taken from Cotes. ${ }^{10}$

Group data are expressed as means with standard deviations in parentheses. Simple correlations were obtained by determining Pearson's rank correlation coefficient.

\section{Results}

Mean (SD) Pemax was $98.3(20.0) \mathrm{cm} \mathrm{H}_{2} \mathrm{O}$ in the 18 men (normal $>80 \mathrm{~cm} \mathrm{H}_{2} \mathrm{O}$ ) and 66.9 (23.5) $\mathrm{cm} \mathrm{H}_{2} \mathrm{O}$ in the seven women (normal > $\left.59 \mathrm{~cm} \mathrm{H}_{2} \mathrm{O}\right)$. Mean PEmax was $64 \%(18 \%)$ predicted; in 16 patients it was below $75 \%$ predicted. Mean PImax was $74.7(30.0) \mathrm{cm}$ $\mathrm{H}_{2} \mathrm{O}$ in the 18 men (normal $>44 \mathrm{~cm} \mathrm{H}_{2} \mathrm{O}$ ) and $50.6(15.7) \mathrm{cm} \mathrm{H}_{2} \mathrm{O}$ in the seven women (normal > $29 \mathrm{~cm} \mathrm{H}_{2} \mathrm{O}$ ); for men and women combined the mean was $64 \%(24 \%)$ predicted and in 14 patients was below $75 \%$ predicted. The mean quadriceps maximal voluntary contraction was $33.8(9 \cdot 1) \mathrm{kg}$ in the 18 men (normal $>24 \mathrm{~kg}$ ) and $20.0(4.8) \mathrm{kg}$ in the seven women (normal > $20 \mathrm{~kg}$ ); for men and women combined the mean was $68 \%(20 \%)$ predicted and in 17 patients the value was below $75 \%$ predicted. Both PEmax and PImax were correlated with quadriceps maximal voluntary contraction (figs 1 and 2). PEmax was weakly correlated with PImax (fig 3).

Mean $\mathrm{FEV}_{1}$ was $46 \%$ (21\%) predicted and FVC 64\% (22\%) predicted. The mean $\mathrm{FEV}_{1} /$ FVC ratio was $60 \%(11 \%)$ and peak expiratory 


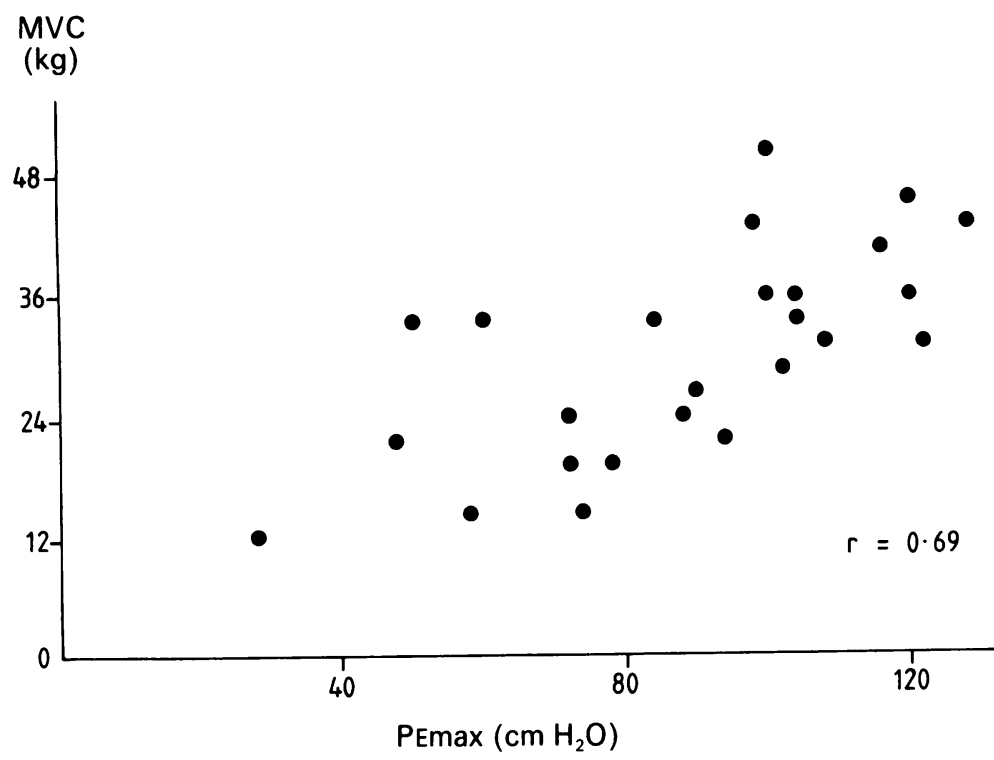

Figure 1 Relation between maximal voluntary contraction (MVC) of quadriceps femoris muscle and maximal static expiratory mouth pressure (PEmax) in 25 patients with cystic fibrosis.

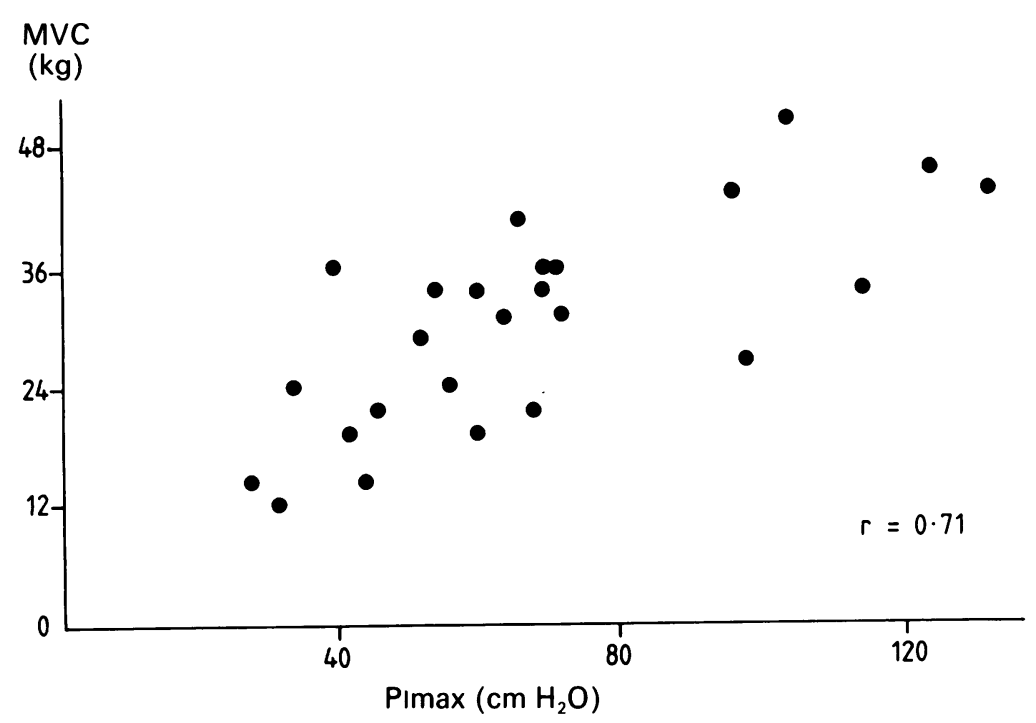

Figure 2 Relation between maximal voluntary contraction (MVC) of quadriceps femoris muscle and maximal inspiratory mouth pressure (PImax).

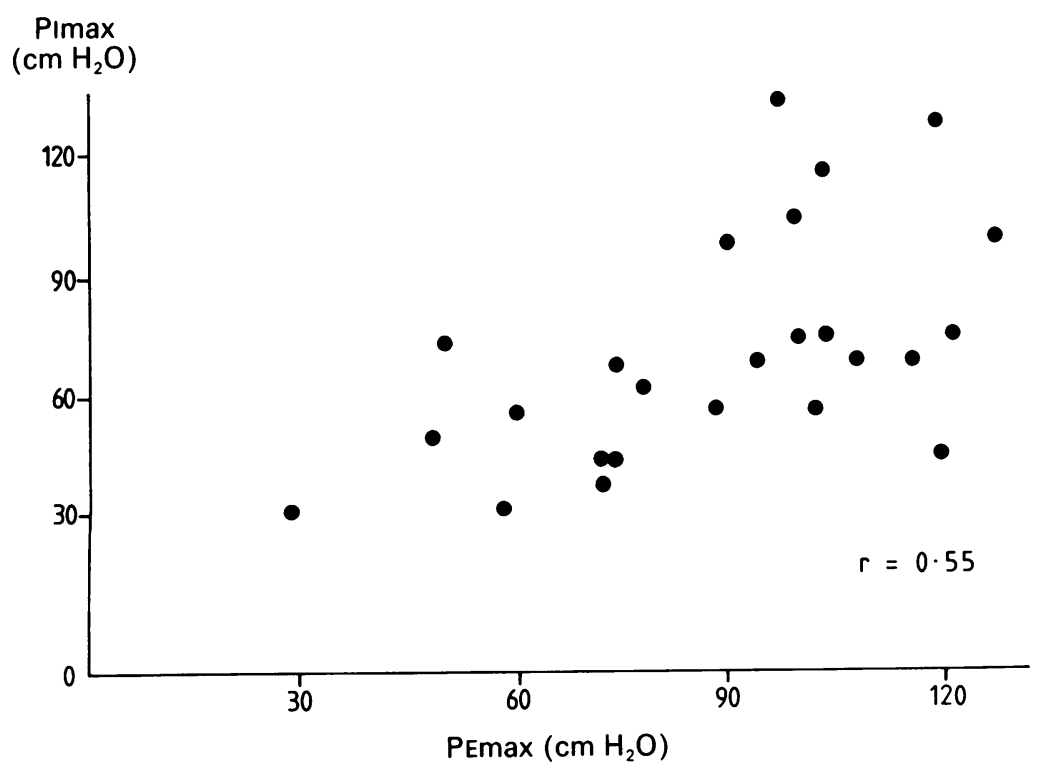

Figure 3 Relation between maximal static inspiratory (PImax) and expiratory (PEmax) mouth pressures. flow was 296 (121) 1/min. TLC was normal $(107 \%(17 \%)$ predicted), RV was increased $(216 \%(85 \%)$ predicted), and vital capacity was reduced $(64 \%(21 \%)$ predicted). Although TLCO was low $(71 \%(17 \%)$ predicted), KCO was normal (113\% (14\%) predicted).

\section{Discussion}

We found that out of 25 patients with cystic fibrosis nine had a PEmax value greater than $75 \%$ predicted, 11 a PImax greater than $75 \%$, and eight a quadriceps maximal voluntary contraction greater than $75 \%$. Previous studies in cystic fibrosis have shown that respiratory muscle strength as judged by PEmax and PImax was normal or above normal ${ }^{67}$; absolute values of PEmax and PImax in these studies were compared with pressures generated in control subjects. We obtained our predicted values from Wilson et $a l,{ }^{8}$ who found that pressures depend on age, sex, weight, and height, and whose control values were similar to those obtained from normal subjects in our laboratory.

Other authors have attempted to relate their pressure results in patients with cystic fibrosis to the lung volume at which their measurements were made. ${ }^{5}$ As our patients had normal total lung capacity lung volume is unlikely to have affected the values of PEmax. By contrast, residual volume in our patients was increased at $216 \%$ predicted and this would be expected to cause a less than optimum length-tension relation of the inspiratory muscles during a PImax manoeuvre performed from RV. This if anything would have caused PImax values to be spuriously low and would have underestimated inspiratory muscle force. Inspiratory muscle force in our group of patients with cystic fibrosis was probably therefore normal or only slightly below normal.

Our patients were at home leading a normal life and had not had an exacerbation of pulmonary infection in the previous three months. Possibly more severe respiratory and quadriceps muscle weakness will develop later as the disease progresses, or severe muscle weakness might have been found had we studied a group of patients with more advanced disease.

Although PEmax and PImax have been measured previously, the strength of other skeletal muscles has not been assessed in patients with cystic fibrosis. We found that quadriceps femoris maximal voluntary contraction was reduced more often than respiratory pressures, but that there was a good correlation between PEmax, PImax, and quadriceps maximal voluntary contraction. As the respiratory muscles are also skeletal muscles, it is not surprising that the strength of these different groups of muscles should be related to each other.

In conclusion, severe respiratory muscle weakness was uncommon in this group of patients with cystic fibrosis who had not had an exacerbation of pulmonary infection over the previous three months. Our results suggest that severe weakness of the respiratory muscles is not a common cause of breathlessness or 
reduced exercise tolerance in patients such as these who have not reached the terminal stages of cystic fibrosis.

1 Arora N, Rochester D. Effect of body weight and muscularity on human diaphragm muscle mass, thickness and area. J Appl Physiol 1982;52:64-70.

2 Arora N, Rochester D. Respiratory muscle strength and maximum voluntary ventilation in undernourished patients. Am Rev Respir Dis 1982;126:5-8.

3 Szeinberg A, England S, Mindorff C, Fraser I, Levison H. Maximal inspiratory and expiratory pressures are reduced in hyperinflated, malnourished young adult male patients with cystic fibrosis. Am Rev Respir Dis 1985;132:766-9.

4 Nickerson BG, Richards W, Wang C, Keens TG. Increased ventilatory muscle strength and endurance in childhood with asthma and cystic fibrosis [abstract]. Fed Proc $1981 ; 540$.
5 Asher MI, Pardy RL, Coates AL, Thomas E, Macklem P. The effects of inspiratory muscle training in patients with cystic fibrosis. Am Rev Respir Dis 1982;126:855-9.

6 O'Neill S, Leahy F, Pasterkamp M, Tal A. The effects of chronic hyperinflation, nutritional status, and posture on respiratory muscle strength in cystic fibrosis. $A m R e v$ Respir Dis 1983:128:1051-4.

7 Marks J, Pasterkamp H, Tal A, Leahy F. Relationship between respiratory muscle strength, nutritional status, and lung volume in cystic fibrosis and asthma. Am Rev and lung volume in cystic

8 Wilson SH, Cooke N, Edwards R, Spiro S. Predicted normal values for maximal respiratory pressures in caucasian adults and children. Thorax 1984;39:535-8.

9 Tornvall G. Assessment of physical capabilities with special reference to the evaluation of maximal voluntary isometric muscle strength and maximal working capacity. Acta Physiol Scand 1963;58(suppl 201).

10 Cotes JE. Lung function: assessment and application in medicine. 4th ed. Oxford: Blackwell, 1979:318 